\title{
Health Status and Life Situation of Street Children in Zahedan, Southeast of Iran
}

\author{
Hossein Ansari, Alireza Ansari Moghaddam, ${ }^{1, *}$ Mahdi Mohammadi, Mostafa Peyvand, ${ }^{1}$ Ab- \\ dorrahman Gorgij, and Fariba Shahraki Sanavi ${ }^{1}$ \\ ${ }^{1}$ Health Promotion Research Center, Zahedan University of Medical Sciences, Zahedan, IR Iran \\ *Corresponding author: Alireza Ansari Moghaddam, Health Promotion Research Center, Zahedan University of Medical Sciences, Zahedan, IR Iran. Tel: +98-9155412155, Fax: +98-5433425375, \\ E-mail:ansarialireza@yahoo.com
}

Received: June 27, 2015; Revised: July 24, 2015; Accepted: July 31, 2015

\begin{abstract}
Background: The children working in the streets are at risk of violence, sexual and substance abuse and infectious diseases. Few studies have been done in this field in Iran and around the world.

Objectives: This study aimed to assess the health status and life situation of street children to encourage and inform interventions and the future research agenda regarding these children in Iran.

Patients and Methods: This cross-sectional study was conducted in southeast of Iran from January to April 2015. Based on postal map, the city was divided into five districts and 216 male street children were selected using snowball sampling. An unstructured questionnaire was provided by integrating eight previously used questionnaires in different studies with approved validity and reliability and filled with in-depth interview. Data were analyzed in Stata 12 software using independent t-test and chi-square test.

Results: The mean age of the subjects was $12.5 \pm 3.2$ years and $29.2 \%$ and $18.9 \%$ of them subsisted by vending and rubbish gathering, respectively. There was significant relation between fathers' job and type of children's activities $(P=0.024)$. The prevalence of smoking and history of alcohol consumption was $42.6 \%$ and $2 \%$, respectively. The lowest mean age of initial use and also the most commonly used substance was for cigarette smoking. The mean age of children with illiterate parents that were using substances or had lost both their parents was lower than the mean age of the rest $(\mathrm{P}<0.05)$. Only $38.6 \%$ of the children ate meals with their families and the rest ate their meals as snack.

Conclusions: The health status and life situation of street children in this region do not seem appropriate and earning money is the most important motivation to being a street child. Unlike violence, the tendency to substance abuse, especially cigarette smoking, was pretty high. On the other hand, the lower age of illicit drug abuse among these children in this study indicates a higher vulnerability of this group. However, the awareness and educational level of the parents is an important determinant in this regard.
\end{abstract}

Keywords: Health Status; Life Situation; Street Children; Zahedan

\section{Background}

A street child is one whom the street has become his/her real home more than his/her family, a situation in which there is no protection, supervision, or direction from responsible adults (1). There are tens of millions of street children that most of them live in low and middle income countries $(1,2)$, but existing research regarding street children and youth has overwhelmingly been conducted in high income countries and the health status and life situation of these children globally is understudied (2).

The previous studies have shown that most common type of work activities among street children are including shoe polishing, selling different goods and scavenging that all of these jobs put them at risk of different diseases and damages $(3,4)$.

A study conducted in Turkey (4) has reported that the educational status of the children and their parents is low and more than $35 \%$ of them exposed to beating and attack. As the results of some other studies $(4,5)$ overall preva- lence of HIV and HBsAg positive among street children are $7.6 \%$ and $24 \%$, respectively. Generally, children living or working in the streets are at risk of violence, sexual abuse and substance addiction and of acquiring infectious diseases including HIV, hepatitis B and other infectious disease (6). Therefore, the health status and life situation of these children is dramatically different from others.

There are limited numbers of studies about street children in Iran. However, a study conducted in Tehran (7) reported that about $61.8 \%$ of street children are working throughout the year and the length of it is associated with economic status of the family. This study also reported that $36.4 \%, 7.8 \%$, and $3.6 \%$ of children have history of smoking, alcohol consumption and other illicit drugs use, respectively and also $77 \%$ of them, who worked during the year, permanently had lower levels of education. Another study conducted in Iran was reported the rate of substance abuse among the street children about $80 \%$ (8).

Copyright (c) 2015, Health Promotion Research Center. This is an open-access article distributed under the terms of the Creative Commons Attribution-NonCommercial 4.0 International License (http://creativecommons.org/licenses/by-nc/4.0/) which permits copy and redistribute the material just in noncommercial usages, provided the original work is properly cited. 
Ansari $H$ et al.

Although the number of such children is estimated more than 200,000 (9), there is little information about health status and life situation of street children in Iran.

Sistan and Baluchistan province is located in the southeast of Iran with a population of about 2,700,000 people (10) that has common borders with Pakistan and Afghanistan. It is worth mentioning that the number of street children is also more in both Afghanistan and Pakistan $(3,6)$. Therefore, traveling and the movement of populations between the two sides of the border influence this issue in this region. As we know, there is no study about these children in Zahedan. Also, the number of street children in southeastern Iran is more than the other areas in Iran (9). Therefore, studying and evaluation of different aspects of this group, especially in this region is too important. It seems that the results of the present study could be helpful for authorities to planning for street children regarding improvement of their living standards and health status.

\section{Objectives}

This study aimed to assess the health status and life situation of street children to encourage and inform interventions and the future research agenda regarding these children in Iran. Due to lack of data in Iran and Sis$\tan$ and Baluchistan province, the results of this study can also provide the basis for comparison in future epidemiological studies.

\section{Patients and Methods}

This cross-sectional study was conducted in Zahedan, southeast of Iran, from January to April 2015. Based on postal map, the city was divided into 5 districts (north, south, center, east and west). Approximately, 43 street children were selected using snowball sampling from each district and a total of 216 subjects were studied. The starting point for sampling in each district was the most crowded locations that street children gathered there. The sampling continued until 43 subjects completed in each defined districts. Street children in this study refer to children 8 to 19 years who spend days and nights on streets with or without family and subsist in the streets in any possible way. The inclusion criteria were as follows: male gender, age ranging from 8 to 19 years and spending at least 3 hours a day in the streets to earn money. Those children who were not willing to cooperate were excluded from the study.

An unstructured questionnaire was provided by integrating 8 previously used questionnaires in different studies. The validity of questionnaire was approved with at least 0.83 Content Validity Index (CVI) for every question by 10 experts and the internal consistency was approved by Cronbach's Alpha equal to 0.76. Three native interviewers were trained how to fill the questionnaires. The used checklists were designed by the researchers and included 45 questions. The parts of the questionnaire were as follows: characteristics and demographic vari- ables, nutritional information, activity status, general information and cause of being street children, and information about high-risk behaviors.

At first, the interviewers took a written informed consent form children by explaining the objectives of the study and emphasizing on confidentiality of their information. They conducted their work under comments of a supervisor. This study was approved by ethical committee of Zahedan university of Medical Sciences. The data were analyzed by Stata.12 software (SPSS, Inc. Chicago, USA) using Independent t-test and chi-square test. P value $<0.05$ was considered as statistically significant.

\section{Results}

\subsection{Demographic Characteristics}

A total of 216 street children were interviewed in this study. All of them were males. Mean age of the subjects was $12.5 \pm 3.2$ years. The $49.8 \%$ of fathers and $58.2 \%$ of mothers of the subjects were illiterate. Also, $93.8 \%$ of children's mothers were housewives. About $88.9 \%$ of their fathers were self-employed that $21.6 \%$ and $27.6 \%$ of them were involved in garbage gathering and retailing, respectively (Table 1). Regarding living status, 3.7\% of the interviewed street children lost their both mother and father and $26 \%$ of them lived with their relatives, grandfather and/ or grandmother. Nearly, $54.2 \%$ of these children reported they do not own home and their family live in a rented house. Only 6 children lived outdoor and slept in parks or private places at nights, but the others finally came back home after work and activities. The length of working time of the street children was $7.8 \pm 3.6$ hours per day. The $84 \%$ of the children worked during the year, permanently.

\subsection{Factors Affecting Street Children's Health}

Children most frequently reported family conflict (including violence (36\%), parental drug use (33\%), physical abuse (33\%) and neglect (32.1\%)) or changes in family structure (death of a parent (26\%), remarriage (35\%), and discrimination (31\%)) as their reasons for being on the street.

Most of the children had lower levels of education and $23 \%$ had a history of dropout. The reasons for leaving school was as follows: not interested in education (11\%), have to work due to poverty and financial reasons (51.8\%), ridiculed by friends or teachers (10.2\%), family banning (16\%) and not being able to learn (11.5\%). According to statements of these children about $29.2 \%, 18.9 \%, 13.5 \%$, and $22.2 \%$ of them subsisted by vending (legal and illegal devices and products), rubbish gathering, shoes making or polishing and beggaring or car washing, respectively. The rest were engaged in other activities or a combination of these activities. There was a statistically significant correlation between the fathers' job and type of children's activities. $(P=0.024)$, so that, the children prefer to do their fathers' activity (Table 1). Eighty seven percent of children 
handed their earnings to the families. Regarding physical activity, all children hiked at least two hours a day.

\subsection{Substance Abuse and Violence}

In this study, $47.4 \%$ of children had smoked cigarette in their lifetime. Prevalence of smoking was $42.6 \%$ and $2 \%$ of them had a history of alcohol consumption. Table 2 shows the frequency distribution of substance abuse among the subjects based on type of the substances among the subjects. About $66.7 \%$ of the subjects had experienced (at least on time used during past year) or were the current user of at least one substance. The lowest mean age of initial use and also the most commonly used substance was cigarette smoking. The average age of children with illiterate parents that were using substances (at least one substance) was $12.89 \pm 2.1$ and significantly lower than the mean age of the rest $(14.09 \pm 3.2)(\mathrm{P}=0.038)$. History of substance abuse among street children who had lost both their parents $(35.4 \%)$ or separated parents $(29.1 \%)$ was significantly higher than the other street children (21.1\%) $(\mathrm{P}=0.042)$. Also, the prevalence of substance abuse among children who their father had a history of at least one substance abuse (30.6\%), as well as in children who had left school (24.6\%) was more than the other children (19.1\%) $(\mathrm{P}=0.048)$.

\begin{tabular}{lcccccc}
\hline Table 1. Frequency Distribution of Street Children's Activity Type According to Their Father's Occupation in Zahedan ${ }^{\mathrm{a}}$ \\
\hline
\end{tabular}

a The values are presented as No. (\%).

b The occupation status of some children's father was unknown and missed.

Table 2. Frequency Distribution and Mean Age of Onset of Different Substance Abuse Experiences and/or Current Consumption Among Street Children in Zahedan a

\begin{tabular}{|c|c|c|c|}
\hline Substance Type & Values & $\begin{array}{l}\text { Age of Initial Abuse } \\
\text { of Each Substance }\end{array}$ & $\begin{array}{l}\text { Substance Used for } \\
\text { the First Time }\end{array}$ \\
\hline No consumption & $72(33.3)$ & - & - \\
\hline Only cigarette & $16(7.4)$ & $12.1 \pm 2.3$ & - \\
\hline Only alcohol & $5(2.3)$ & $14.1 \pm 4.3$ & - \\
\hline Only nas ('plant material') & $20(9.2)$ & $14.5 \pm 2.6$ & - \\
\hline Cigarette and betel quid ('pan') & $5(2.3)$ & $12.2 \pm 2.9$ & Cigarette \\
\hline Cigarette and nas ('plant material') & $20(9.2)$ & $12.3 \pm 4.3$ & Cigarette \\
\hline Cigarette and opium & $5(2.3)$ & $12.3 \pm 3.3$ & Cigarette \\
\hline Cigarette, hookah and opium & $8(3.7)$ & $12.7 \pm 3.7$ & Cigarette \\
\hline Cigarette, hookah and betel quid ('pan') & $10(4.6)$ & $13.2 \pm 1.3$ & Cigarette \\
\hline Cigarette, hookah and nas ('plant material') & $11(5.1)$ & $11.9 \pm 1.8$ & Cigarette \\
\hline Cigarette, opium and nas ('plant material') & $9(4.2)$ & $14.1 \pm 2.3$ & Cigarette \\
\hline Cigarette, opium and betel quid ('pan') & $8(3.7)$ & $14.3 \pm 4.3$ & Cigarette \\
\hline Betel quid ('pan') and nas ('plant material') & $12(5.5)$ & $13.9 \pm 2.8$ & Nas ('plant material') \\
\hline Hookah and nas ('plant material') & $4(1.8)$ & $15.3 \pm 2.1$ & Nas ('plant material') \\
\hline Hookah, nas ('plant material') and betel quid ('pan') & $7(3.3)$ & $15.1 \pm 2.9$ & Nas ('plant material') \\
\hline $\begin{array}{l}\text { Cigarette, opium, hookah, betel quid ('pan') and nas } \\
\text { ('plant material') }\end{array}$ & $4(1.8)$ & $13.4 \pm 2.1$ & Cigarette \\
\hline
\end{tabular}

$\mathrm{a}$ The values are presented as mean $\pm \mathrm{SD}$ or No. (\%). 
Ansari $H$ et al.

None of the street children had a history of conviction, self-injuring, unsafe sexual behavior, using shared needle and attempt to suicide. Only 8.3\% reported that they carried knife with themselves and $13.8 \%$ stated that they experienced at least one street fight during the last year. However, in total, 47.7\% (CI 95\%: 44\%-51\%) of children mentioned high-risk behaviors [committing at least one of behaviors including substance abuse from any type (use for at least two months continuously), violence, carry any weapon, unsafe sexual behaviors, attempt to suicide, inactivity and leaving home or school].

\subsection{Nutrition Status, Health, and Disease}

The nutritional status of these children did not seem appropriate, so that none of them received adequate protein and vitamins based on their reports using prepared questionnaire (by supervision of a nutritionist). For example, $69 \%$ of the subjects stated that they have not eaten meat (even one time) and fish during last year. On the other hand, none of them had a history of satiety in none of the meals. Only $38.6 \%$ of the children reported that they eat meals with their families and the rest stated that they eat their meals as a snack.

About 18\% of these children had a history of at least one disease that referred to the doctor and $15.6 \%$ felt discomfort in different parts and organs of the body; however, due to lack of money they never referred to the doctor. In total, the children reported limited access to health care and based on their declaration the barriers included lack of enough money, minority status, stigmatization by providers, distrust in quality of care and difficulty finding time to seek care. None of the subjects had knowledge about HIV and hepatitis infection and those transmission routes. Only three children stated that they heard only the name of this disease or "AIDS".

\section{Discussion}

It has been thought that street children are not at risk and the consequences of increasing of them in society have been forgotten. However, this study showed that the health status and life situation of street children in this region does not seem appropriate and earning money is the most important motivation to being a street child. Although the street children in southeastern Iran have not violent life, tendency to substance abuse, especially cigarette smoking was pretty high. On the other hand, lower age of illicit drug abuse among these children in this study indicates the higher vulnerability of this group. This situation could bring many problems for health system and society in the future. It can be concluded that increasing awareness and educational level of the parents and organizing these children can efficiently prevent from this phenomenon in the societies.

This study showed that more than half of the children's parents are illiterate and live in a rented house and 23\% had a history of dropout. Moreover, $47.4 \%$ of children had smoked cigarette in their lifetime and mean age of the initial substances abuse was very low. Regarding nutritional status, about $62 \%$ of the children reported that they eat their meals as a snack. Therefore, it can be concluded that the health status and life situation of street children in southeast of Iran is inappropriate and needs more attention.

Obviously, street child is an example of the global and national disparity in child health. The available literature $(3,7-9,11,12)$ shows that often the street children engage disproportionately in high-risk behaviors and low level of health status and life situation. On the other hand, exposure to high-risk behaviors and living in poor shelter and places could be resulted in disproportionate morbidity in the areas of infectious illness, psychiatric disease, reproductive health, and, less growth (2). It is clear that to take appropriate actions in this field, studying the health status and life situation of street children in different regions seems to be important. Otherwise, collecting data about health status and life situation of street children can be the first step for any intervention. For example, the present study indicated that the children have limited access to health care due to barriers included cost, minority status, stigmatization by providers and difficulty finding time to seek care because of lost earnings. Moreover, none of the subjects had knowledge about HIV and hepatitis infection and those transmission routes. Therefore, these results show that the prevalence of infectious disease and psychological problems might be increased in the future among this group and consequently in the society. However, the health authorities should discover and check the vaccination history and immunize some infectious diseases such as hepatitis B as well as plan for street children regarding improvement of their living standards and health status in Iran, especially in this region.

The results showed that more than a quarter of the street children lived with their relatives or grandparents. Although this rate was lower than that in the previous study in Tehran (7), the results showed the important role of Iranian families. However, family disruption is an important factor in the street youth phenomenon, and having a place for living might be more important than poverty (13). Therefore, providing a place at least for homeless children can decrease many problems regarding these children.

Based on the results of this study almost half of their parents were illiterate that is more than that in the previous study conducted in Tehran (7) and is in accordance with the results of a study in Pakistan (14). As another result, $87 \%$ of children gave their income to the family that is more than study conducted in Tehran (7). This result accounts the low economic level of the families and it is against children's rights.

Although $8.3 \%$ of children carried knife with themselves and $13.8 \%$ stated that they experienced at least one street fight during the last year; however, none of them had a history of conviction, self-injuring, unsafe sexual behavior, 
using shared needle and attempt to suicide. This result is not parallel with previous study in Tehran (7), Turkey (4), and Nigeria (15), which reported $8.3 \%, 15 \%$ and $1.3 \%$ of the studied street children have a history of incarceration, antisocial behavior and conviction, respectively. It can be concluded that most of these children in southeastern Iran come to street for financial incentives and livelihoods.

The prevalence of smoking was $42.6 \%$, but only $2 \%$ of them had a history of alcohol consumption. This result is not in line with findings of the previous studies in Tehran (7) and Turkey (4) and the smoking prevalence among street children in southeast of Iran is more than those in Tehran and Turkey. The lowest mean age of initial use and also usually firstly used substance is for cigarette smoking and the average age of substance abuse was related to life status and educational level of the parents, especially their father. Lower age of illicit drug abuse among these children indicates that these groups are more vulnerable to adverse environmental conditions that may result in high prevalence of violence and addiction in societies. The most commonly used substance was cigarette; so, it seems that the cigarette smoking is the most important initiator for other types of substance abuse among children. Given the life situation of street children in this study, this group is vulnerable to psychosocial and physical problems which can impose more burdens on health care system. Also, only $38.6 \%$ of the children ate meals with their families and most of them ate their meals as a snack. Therefore, they would be at risk of many infectious and chronic diseases $(2,6,16)$.

This study showed that the street children tended to have more diverse occupations with less income, primarily from peddling and shoes making up to rubbish gathering. Selling different goods and scavenging were the most common types of work activities among the subjects in this study that is consistent with results reported in Turkey (4) and Pakistan (13). Given the job status of children's fathers in this study, it seems that the street children usually choose the jobs like their fathers. As their father did not have an appropriate job, thus this situation could affect the health status and life situation of street children more and more.

Unlike capital (8), but like Turkish (4) and Pakistani (3) street children, most of street children in southeast of Iran are male. Because of the region's conditions and cultural issues, the girls could not be able to work on the streets. The mean age of children in this study was 12.5 that is less than those of street children in Tehran (7) and Turkey (4). About 10\% of the subjects were less than 9 years that is parallel with the result of a study conducted in Tanzania (17). However, $23 \%$ had a history of dropout that was lower than Turkey (4) but more than Tehran (7), the capital of Iran. Unfortunately, the children in this region usually follow each other and hope to earn money and help their family, dropout and become street children. On the other hand, the families in the area are populous and the parents cannot manage all members of the family solely. Therefore, not only the children have to work, but the parents encourage them to work and provide scholarship. However, this will lead to many consequences in the next years and the authorities should do the main action and organize these children. In this regard, meeting the parents and awarding scholarship to children could be effective.

\section{Acknowledgements}

The authors appreciate the children participated in this study and their family.

\section{Authors' Contributions}

Hossein Ansari and Alireza Ansari Moghadam were project managers and designers of the research. Mahdi Mohammadi and Fariba Shahraki Sanavi collaborated in analyzing data and writing the paper. Mostafa Peyvand and Abdorrahman Gorgij collaborated in collecting data and prepared the literature review.

\section{Funding/Support}

This study was financially supported by Zahedan university of medical sciences.

\section{References}

1. UNICEF Executive Board UE. Exploitation of working children and street children1983. USA: 1986.

2. Woan J, Lin J, Auerswald C. The health status of street children and youth in low- and middle-income countries: a systematic review of the literature.J Adolesc Health. 2013;53(3):314-321 e12.

3. Ali M, Shahab S, Ushijima H, de Muynck A. Street children in Pakistan: a situational analysis of social conditions and nutritional status. Soc Sci Med. 2004;59(8):1707-17.

4. Turkmen M, Okyay P, Ata O, Okuyanoglu S. A descriptive study on street children living in a southern city of Turkey. Turk J Pediatr. 2004;46(2):131-6.

5. Karmacharya D, Yu D, Dixit S, Rajbhandari R, Subedi B, Shrestha $\mathrm{S}$, et al. A study of the prevalence and risk factors leading to HIV infection among a sample of street children and youth of Kathmandu. AIDS Res Ther. 2012;9(1):25.

6. Ali M, de Muynck A. Illness incidence and health seeking behaviour among street children in Rawalpindi and Islamabad, Pakistan - a qualitative study. Child Care Health Dev. 2005;31(5):525-32.

7. Ahmad Khaniha AR, Hakim Shooshtari M, Mohammadian M, Bidaki R, Pourrashidi Boshrabadi A. Familial characteristics of street children in tehran, iran. Iran J Psychiatry Behav Sci. 2014;8(2):86-9.

8. Navipour R, Mohebbi MR. Street children and runaway adolescents in Iran. Indian Pediatr. 2004;41(12):1283-4.

9. The support Committee for Iranian's street children. Iran has over 200000 street children. 2005. Available from: http://www. Iranstreetchildren.com /index. php/article/more/http://www. Iranstreetchildren.com /.

10. Miri-Moghaddam E, Zadeh-Vakili A, Rouhani Z, Naderi M, Eshghi P, Khazaei Feizabad A. Molecular basis and prenatal diagnosis of beta-thalassemia among Balouch population in Iran. Prenat Diagn. 2011;31(8):788-91.

11. Cavalcante-Nobrega LP, Mello AF, Maciel MR, Cividanes GC, Fossaluza V, Mari JJ, et al. Quality of life of mothers whose children work on the streets of Sao Paulo, Brazil. Cad Saude Publica. 2015;31(4):827-36.

12. Senaratna BC, Wijewardana BV. Risk behaviour of street children in Colombo. Ceylon Med J. 2012;57(3):106-11. 


\section{Ansari $H$ et al.}

13. Abdullah MA, Basharat Z, Lodhi O, Wazir MH, Khan HT, Sattar NY, et al. A qualitative exploration of Pakistan's street children, as a consequence of the poverty-disease cycle. Infect Dis Poverty. 2014;3(1):11.

14. Veale A, Donà G. Street children and political violence: a sociodemographic analysis of street children in Rwanda. Child Abuse Negl. 2003;27(3):253-69.

15. Olley BO. Social and health behaviors in youth of the streets of
Ibadan, Nigeria. Child Abuse Negl. 2006:30(3):271-82.

16. Greksa LP, Rie N, Islam AB, Maki U, Omori K. Growth and health status of street children in Dhaka, Bangladesh. Am J Hum Biol. 2007;19(1):51-60.

17. McAlpine K, Henley R, Mueller M, Vetter S. A survey of street children in northern Tanzania: how abuse or support factors may influence migration to the street. Community Ment Health J. 2010;46(1):26-32. 